\title{
Opportunities for Instrumentation Funding - US Army Research Office
}

Robert J. Kokoska ${ }^{1}$

${ }^{1}$ US Army Research Laboratory, US Army Research Office, Physical Sciences Directorate, Research Triangle Park, NC

Each year, the Department of Defense (DoD) releases a program announcement for the Defense University Research Instrumentation Program (DURIP). DURIP is part of the DoD University Research Initiative (URI) and is designed to improve the capabilities of accredited United States (U.S.) institutions of higher education to conduct research and to educate scientists and engineers in areas important to national defense, by providing funds for the acquisition of research equipment or instrumentation. This program is administered by three agencies: the Army Research Office (ARO), the Office of Naval Research (ONR) and the Air Force Office of Scientific Research (AFOSR).

Grant proposals for the DURIP program should address the impact of the equipment or instrumentation on the institution's ability to educate students through research in disciplines important to DoD missions. As it pertains to the Army Research Office, those appropriate disciplines are outlined in the ARO Core Broad Agency Announcement (BAA) for Basic and Applied Scientific Research [1]. This announcement provides descriptions of the forty ARO research programs executed through ten scientific divisions: Chemical Sciences, Physics, Life Sciences, Mechanical Sciences, Electronics, Materials Science, Earth Science, Computing Science, Mathematical Sciences and Network Science. Those interested in the DURIP program are encouraged to contact the Program Managers listed in the ARO Core BAA before submitting proposals to explore specific research areas of mutual interest between the University and ARO. This presentation will provide open discussion on additional details of the MURI program including evaluation criteria for proposals, DURIP-specific funding restrictions and effective strategies for the development of quality DURIP proposals.

References:

[1] Broad Agency Announcement for US Army Research Office: https://www.arl.army.mil/www/pages/8/W911NF-17-S0002,\%20ARO\%20Core\%20BAA\%20Amendment\%2002.pdf 

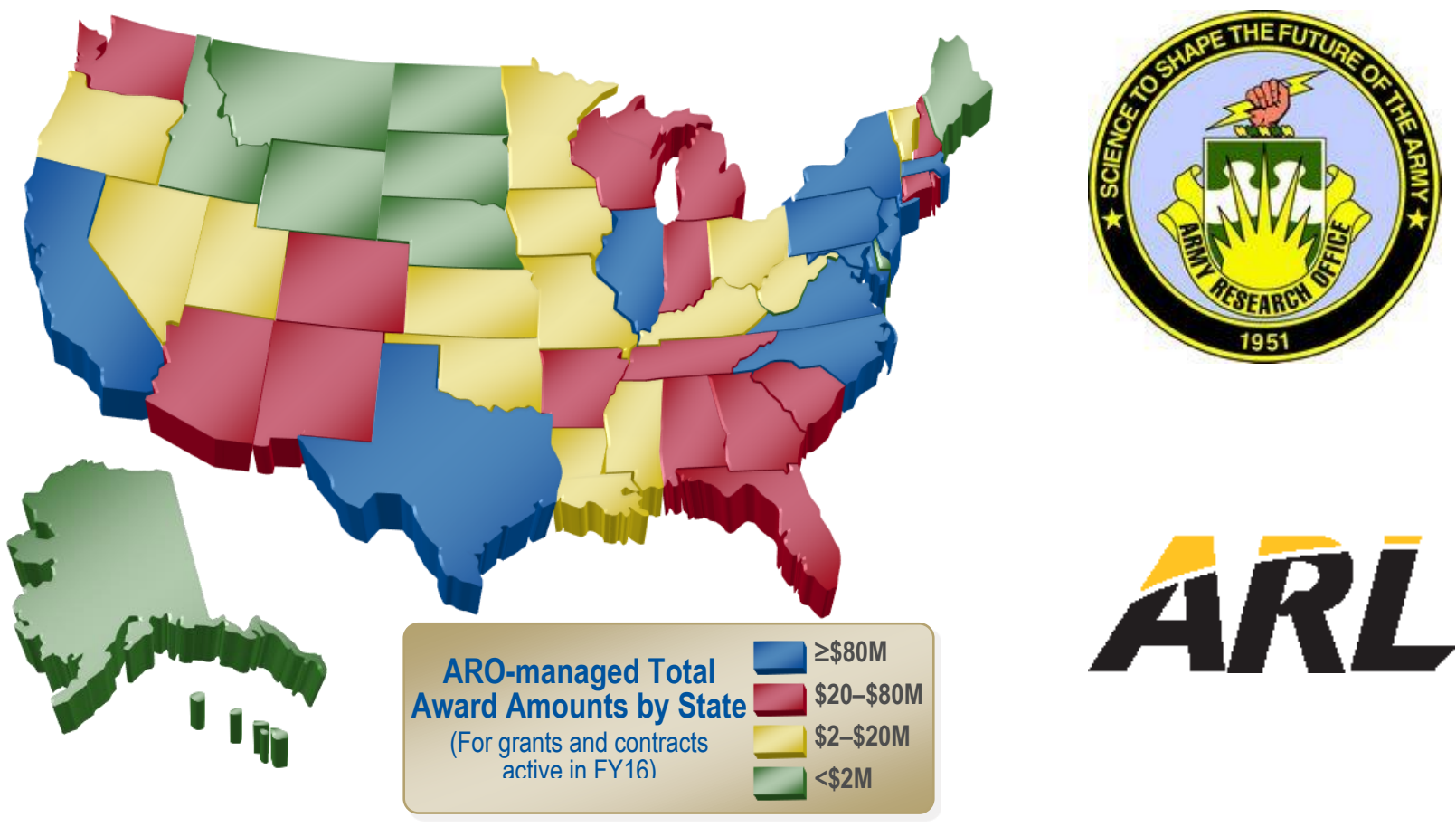

Figure 1. The Army Research Office (ARO), an organization within the Army Research Laboratory (ARL), is responsible for the ARL Extramural Research Campaign and is ARL's principal conduit to engage the university research community. ARO's strategy is to utilize the vast intellectual capital of the world's universities to conceive of and exploit scientific opportunities for unprecedented Army capabilities and to drive science to develop solutions to existing Army technology needs. ARO funds research in all 50 states and throughout the world at over 270 institutes of higher learning and to over 1100 individual investigators. In addition to basic research grants, The Defense University Research Instrumentation Program (DURIP) provides funds for equipment and instrumentation to support research in areas important to national defense. 